\title{
Application of factor analysis for agile supply chain classification: A case study on the Iranian automotive parts supplier (SAPKO)
}

\author{
Davood Rafeie rad ${ }^{\mathrm{a}}$, Maghsoud Amiri ${ }^{\mathrm{a}}$, Masoumeh Gardeshi ${ }^{\mathrm{a}}$ and Javad Siahkali Moradi ${ }^{\mathbf{b}}$
}

${ }^{a}$ Department of Management and Accounting, Allameh Tabatabaee, Tehran, Iran

${ }^{b}$ Department of Management, Islamic Azad University, Research and Science Branch, Tehran, Iran

A R T I C L E I N F O AB S T R A T

Article history:

Received March 20, 2011

Received in Revised form

June, 15, 2011

Accepted 16 June 2011

Available online

18 June 2011

Keywords:

Agile supply chain

Factor analysis

Principal component analysis

Automobile industry

\begin{abstract}
Today automotive companies must pioneer in strategies such as the agile supply chain for competition and various demands of customers. Considering the importance of agile in choosing a supplier at the supply chain, this study tries to identify and evaluate agile activities in SAPCO Company suppliers. Then, using principal component analysis of factor analysis, a number of related activities are divided into smaller groups called factor. The results are used by SAPCO to determine agile patterns in selecting a supplier with emphasis on similarities and differences and create agile portfolio. The study can help SAPCO identify criteria and making decision in the field of agile at suppliers.
\end{abstract}

(c) 2011 Growing Science Ltd. All rights reserved.

\section{Introduction}

Today enterprises are surviving in a drastic competitive environment and facing more challenges. Many practical instances have proved that enterprise must have collaboration capability with other enterprises within supply chain in order to succeed (Song et al., 2007). For businesses to compete in the commercial sector where markets are increasingly more volatile, and unpredictable demands create uncertainty, their supply chains have needed to adapt to respond to such unpredictability. This capability of a supply chain to become flexible is referred to as agility (Christopher, 2000; Prater et al., 2001). To win the competition in the global manufacturing environment the cooperation and collaboration among enterprises play a key role in the current years (Hellard, 1995). This global partnership can be seen in the philosophy of agile manufacturing. Agile supply is more pragmatically defined and closely associated with 'quick response', agile supply drivers are typified by innovative products and unstable demand (Strattona \& Warburton, 2003).

According to Luo et al. (2009) there are three reasons for selecting appropriate suppliers. The first reason is associated with increase trend on implementation of outsourcing which impacts the * Corresponding author. Tel: +98-912-2520885

E-mail addresses: syahkaly@gmail.com (J. Siahkali Moradi) 
suppliers' performance on purchasers (Weber \& Ellram, 1993). Secondly, the trend towards supplybased reduction increases the impact that any given supplier is likely to have on a purchaser's performance (Power et al., 2001). The third reason and maybe the most important one is associated with the the trend towards closer relationships between vendors and purchasers based on collaboration and co-operation increases the role and contribution of suppliers in the operations of the purchaser (Heide \& John, 1990).

Since the need for agile supply chain is working with the agile suppliers, the issue of selecting an agile supplier is important based on of agile criteria. However, agile supply chain involves many complicated relationship and complex activities. Therefore, many researcher and developers apply agent technology to supplier chain management. Any potential supplier may need to be assessed against multiple and often conflicting criteria, between which trade-offs are typically required (Chen et al., 2006).

The other issue, which makes the selection difficult, is that different potential suppliers may have different performance characteristics for different attributes (Xia \& Wu, 2007). For instance, the potential suppliers who can provide raw materials at the lowest prices may not have the best quality or after-sales service among the competing suppliers. Therefore, supplier selection is an inherently multi-objective decision, which looks to minimize some evaluation criteria and, at the same time, maximizing others (Dickson, 1966). These factors are combined to make supplier selection in agile supply chain a complex form. We may expect that purchasing and supply managers would look to use quantitative methods to help inform their decision-making (Luo et al., 2009).

It is evident that many firms are accomplishing a variety of supplier selection activities, which is not formally categorized. Hence, a systematic classification of the current supplier selection activities might provide basic knowledge about the nature and type of supplier selection dimensions and permit a predictive model development for further research on suppliers selection. This paper aims to introduce an application of factor analysis for illuminating and classifying supplier selection activities. The detailed objectives of this study are:

- to propose a tactical methodology, which enables academia and managers to classify diverse and obscure information of suppliers selection activities and to understand distinct dimensions of the information bundle (e.g. types of suppliers selection activities),

- to use principal component analysis as data extraction method in factor analysis,

- to allow practitioners for designing types of suppliers selection activities and to determine suppliers selection portfolio based on a relevance emergency matrix.

\section{Definitions}

\subsection{Agile supply chain}

The agile supply chain (ASC) is an operational strategy, which aims on inducing speed and flexibility in a supply chain (Song et al., 2007). Gunasekaran (1998, 1999) describes agile manufacturing as "the capability to survive and prosper in a competitive environment of continuous and unexpected change by reacting quickly and effectively to changing markets, driven by customer-designed products and services', Goldman et al. (1995) present a slightly different definition, with agile manufacturing. In fact, they allow companies to operate profitably in a competitive environment of continually and unpredictably changing customer opportunities. Both definitions apply to the automotive industry's goals of operating profitably, and sensing and responding effectively to changing demand trends. Basically, the implementation of an agile manufacturing system create an opportunity for an automotive company to re-allocate production line capacity to products, which are in higher than expected demand, rapidly launch new products and yet retain production ability for other products with lower than expected demand (Elkins et al., 2004). An ASC is a dynamic alliance among members of companies to exchange the formation of the necessary things in response to fastchanging markets (Luo, et al., 2009). In ASCs, the task of supplier selection is thus not a one-off 
infrequent activity. Rather, changing market requirements and customer preferences require a broader and faster supplier selection process (Sarkis, 2001; Arteta \& Giachetti, 2004), which requires the use of a wide set of selection criteria (Yusuf et al., 1999; Cagliano et al., 2004).

Some of the conditions in which an agile approach is best suited can be described by the following characteristics: (i) short life cycle products; (ii) high product variety in the face of unpredictable demand; (iii) small volumes and higher profit margins; (iv) competition based on product specification. With this agility, the supply chain more frequently operates in a global context and there is an increasing trend to outsource the supply and manufacturing overseas through a complex supply network (Prater et al., 2001; Masson et al., 2007; Storey et al., 2005) to reduce costs.

\subsection{Factor Analysis}

In this paper, in order to identify the most effective activities for selecting a supplier, we propose to use factor analysis (FA) technique.

The FA is a data and variable reduction technique, which attempts to partition a given set of variables into groups of maximally correlated variables. FA helps convert a large number of variables into a smaller number of variables, called factors, which capture as much information as possible from the original data set (Parasuraman et al., 2004). As an interdependence statistic tool, FA is based on three main assumptions (Jolliffe, 2002):

- Variables are linearly related to each other,

- Data are interval scaled,

- The rating given to any one variable (called factor loading) is partially the result of the influence of other variables.

Depending on the purpose of factor analysis, principal component analysis (PCA) or common factor analysis (CFA) are used as analysis model. The former is applied when a survey purposes to reduce a large number of initial variables into a possibly small number of variables for forecasting while the latter is used when a survey aims to find out correlations among variables (Parasuraman et al., 2004). In this paper we use the (PCA) as analysis model.

\subsubsection{Principal component analysis (PCA)}

Principal component analysis (PCA) is a technique, which reduces the number of variables in an attempt to eliminate the interrelated variables by transforming the system into a smaller system with fewer number of correlated variables called principal components (PCs) or factors (Jolliffe, 2002; Tziakas et al., 2007). FA was first initiated by extraction of an initial solution using PCA. In the present analysis, screen plots were inspected and factors (clusters) with Eigen values greater than 1 were retained (Field, 2005). Varimax rotation was then executed with identification of variables comprising a factor (cluster) based on loadings greater than 0.5 (Field, 2005). The threshold value of 0.5 has been commonly used (Field, 2005; Stevens, 1986). For each identified cluster, a cluster score is extracted. These scores indicate the subjects' predicted values for each cluster and they are calculated based on the factor weights and the original variable values. In summary, for the calculations of PCA, we need to do the following:

First, the mean needs to be subtracted from each of the data dimensions, then, we calculate the covariance matrix. Second, eigenvectors and Eigen values have to be calculated. Eigenvectors appear as diagonal dotted lines on the plot, and they are perpendicular to each other (Smith, 2002). 


\section{Research methodology}

To classify diverse ASC activities, the proposed methodology in this article consists of these phases (Fig. 1).

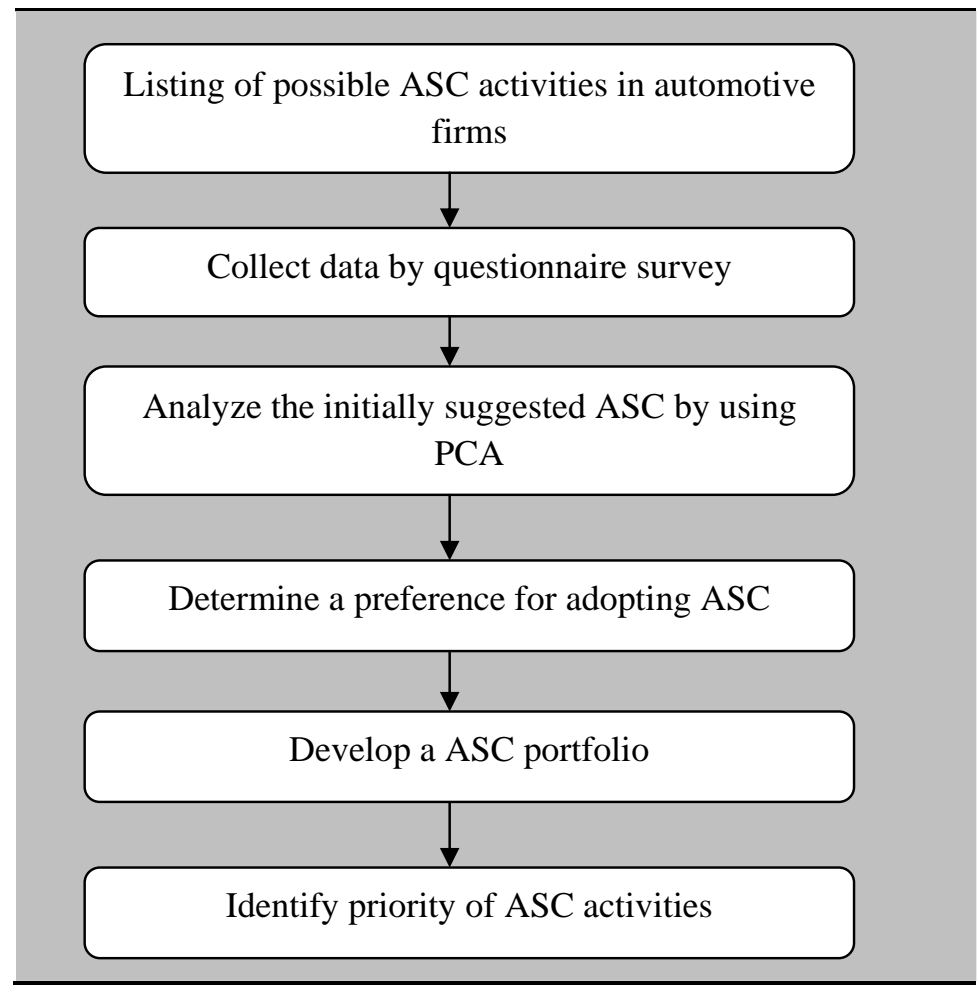

Fig.1. The proposed methodology

\subsection{Data collection and listing of possible ASC activities}

Referring to relatively well-known ASC activities in manufacturing and related work on ASC, managers generate ideas of ASC activities. Table 1 presents a generic sample of ASC activities suggested by intensive group discussions of ASC experts. More number of activities could be added or some could be excluded upon the ASC manager's goal and interest.

\subsection{Questionnaire survey}

Top managements of automotive firms are asked about the implementation level of various areas of ASC. The respondents estimate their ASC activities using a questionnaire sheet based on a Likertscaling. All variables included in the questionnaire were set on a five-point scales $(5=$ extremely important, 4=very important, 3=important, 2=somewhat important, 1=not important) and these scales were used to conduct factor analysis. As the methodology aims to obtain data directly from the target firms, ASC researchers have to consider that the variables have to be formulated in a possibly fieldoriented language.

\subsection{Classification of ASC activities}

A large number of collected data based on the initially suggested ASC activities are analyzed by using PCA as data extraction method. First, the mean value has to be subtracted from each of the data dimensions. Then, initial Eigenvalue and extraction sums of squared loadings in total variance are calculated. The squared loadings (also called factor loadings) with orthogonal factor rotation allow to identify the number of few components and reliability of the extracted components. 


\subsection{Priority of ASC}

Managers in ASC determine a preference for adopting ASC in their firms with mean values of the initial ASC activities.

\subsection{ASC portfolio}

Finally, ASC managers can develop an ASC portfolio using mean values of few extracted components on the competence-emergency matrix. On the vertical axis, for instance, competence serves as a measure of the importance of the ASC activities for an automotive firm. On the horizontal axis, emergency presents a measure of the timing of the ASC activities. The competence -emergency matrix defines four types of ASC units (Fig. 2).

1- High competence and high emergency: Automotive firms often need heavy investment and pay more attention in ASC activities because they involve good opportunities for ASC in future.

2- High competence and low emergency: These ASC activities need much investment and pay more attention, but it can be distributed for some periods.

3- Low competence and high emergency: In this case automotive firms often require ASC activities to fast moving in 'innovative' markets where there is a volatile and unpredictable demand for short life cycle.

4- Low competence and low emergency: These ASC activities need elimination.

\section{Table1}

ASC activities

\begin{tabular}{ll}
\hline 1. Integrating business & 11. Innovation based on customer requirements \\
2. Product and process development cycle & 12. Customer satisfaction \\
\hline 3. Participatory planning & 13. Delivery Speed \\
\hline 4. Integrating process & 14. Retain and grow customer relationships \\
5. Cost reduction & 15. Close relationships with supplier \\
6. Quality Improvement & 16. Strategic relationship with customers \\
7. Innovation ability & 17. Customer and supplier confidence \\
8. Multi-functional staff & 18. Using modern communication equipment \\
9. Continuous staff training and development & 19. Technological cooperation \\
\hline 10. New product introduction & 20. Ability of IT in companies \\
\hline
\end{tabular}

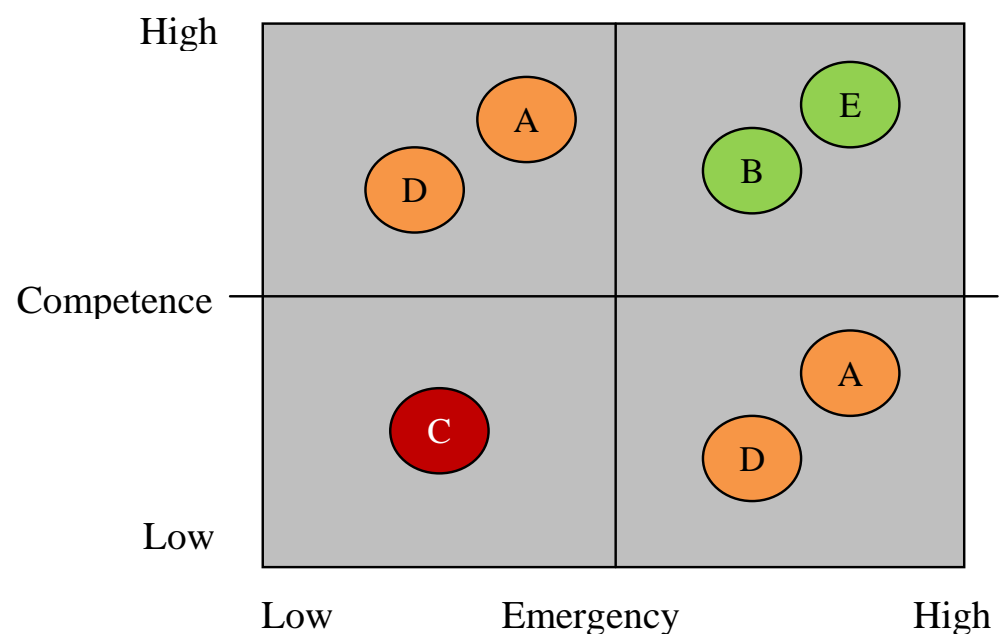

Fig. 2. Example of ASC activities portfolio 


\section{Case study}

\subsection{Data collection}

We invited automotive parts suppliers in Iran to participate in our survey and the questionnaires were collected from all the participating firms. Table summarizes 21 ASC activities suggested as initial variables. Respondents indicated their agreement with each variables, using a five-point Likert scale (5=extremely important, 4=very important, 3=important, 2=somewhat important, 1=not important) for all ASC activities.

\subsection{Classification of ASC activities}

Collected data were analyzed using PCA of factor analysis (Lee \& Lee, 2011). Table 2 demonstrates Eigen values, percent of variance, and cumulative percent in three types such as initial Eigen values, extraction sums of squared loading, and rotation sums of squared loading. Eigen values showed that factors 1-5 would be extracted because their Eigen values were more than 1 . The cumulative percentage of variance explained by these factors was $70.09 \%$, meaning that a considerable amount of the common variance shared by the 21 variables could be accounted for by these five factors. Factor values had to be rotated in order to interpret the solution set more easily (Ocal et al., 2007). After factor rotation, variables were loaded maximally to only one factor and minimally to the remaining factors (Field, 2000). In Varimax rotation, factors are uncorrelated because they are rotated at right angles to each other ( Ghosh \& Jintanapakanont, 2004).

Table 2

Total variance explained using PCA

\begin{tabular}{|c|c|c|c|c|c|c|c|c|c|}
\hline \multirow{2}{*}{ component } & \multicolumn{3}{|c|}{ Initial Eigen values } & \multicolumn{3}{|c|}{$\begin{array}{l}\text { Extraction sums of squared } \\
\text { loadings }\end{array}$} & \multicolumn{3}{|c|}{$\begin{array}{c}\text { Rotation sums of squared } \\
\text { loadings }\end{array}$} \\
\hline & Total & $\begin{array}{c}\% \text { of } \\
\text { variance }\end{array}$ & $\begin{array}{c}\text { Cumulative } \\
\%\end{array}$ & Total & $\begin{array}{c}\% \text { of } \\
\text { variance }\end{array}$ & $\begin{array}{c}\text { Cumulative } \\
\% \\
\end{array}$ & Total & $\begin{array}{c}\% \text { of } \\
\text { variance }\end{array}$ & $\begin{array}{c}\text { Cumulative } \\
\%\end{array}$ \\
\hline 1 & 6.078 & 27.23 & 27.23 & 6.078 & 27.23 & 27.23 & 2.897 & 14.35 & 14.35 \\
\hline 2 & 3.268 & 14.98 & 42.21 & 3.268 & 14.98 & 42.21 & 2.603 & 13.84 & 28.19 \\
\hline 3 & 1.906 & 12.23 & 54.44 & 1.906 & 12.23 & 54.44 & 2.231 & 12.87 & 41.06 \\
\hline 4 & 1.741 & 8.79 & 63.23 & 1.741 & 8.79 & 63.23 & 2.024 & 12.35 & 53.41 \\
\hline 5 & 1.398 & 6.86 & 70.09 & 1.398 & 6.86 & 70.09 & 1.816 & 11.68 & 65.09 \\
\hline 6 & 1.256 & 5.56 & 75.65 & 1.256 & 5.56 & 75.65 & 1.675 & 10.56 & 75.65 \\
\hline 7 & 0.987 & 4.22 & 79.87 & & & & & & \\
\hline 8 & 0.958 & 3.56 & 83.43 & & & & & & \\
\hline 9 & 0.879 & 2.74 & 86.17 & & & & & & \\
\hline 10 & 0.787 & 2.55 & 88.72 & & & & & & \\
\hline 11 & 0.621 & 2.14 & 90.86 & & & & & & \\
\hline 12 & 0.569 & 1.98 & 92.84 & & & & & & \\
\hline 13 & 0.526 & 1.75 & 94.59 & & & & & & \\
\hline 14 & 0.428 & 1.43 & 96.02 & & & & & & \\
\hline 15 & 0.375 & 1.12 & 97.14 & & & & & & \\
\hline 16 & 0.296 & 0.89 & 98.03 & & & & & & \\
\hline 17 & 0.246 & 0.72 & 98.75 & & & & & & \\
\hline 18 & 0.212 & 0.53 & 99.28 & & & & & & \\
\hline 19 & 0.189 & 0.39 & 99.67 & & & & & & \\
\hline 20 & 0.142 & 0.24 & 99.91 & & & & & & \\
\hline 21 & 0.085 & 0.09 & 100 & & & & & & \\
\hline
\end{tabular}

Final statistics in rotated component matrix using Varimax rotation method are present in Table 3. Small quadrangles in Table 3 explain five final components (or factors) based on their factor loadings. Any value larger than 0.6 is considered to be as an acceptable value (Hu \& Bentler, 1999). Since the value of factor loading for the initial component of 'Integrating process' and ' Technological 
cooperation' are smaller than the acceptable value, we have ignored this component in our further analysis.

Table 3

Final statistics in rotated component matrix

\begin{tabular}{lccccc}
\hline & \multicolumn{3}{c}{ Component } \\
\cline { 2 - 6 } & 1 & 2 & 3 & 4 & 5 \\
\hline Integrating business & 0.420 & $\mathbf{0 . 8 7 5}$ & 0.399 & 0.288 & 0.154 \\
\hline Product and process development cycle & 0.368 & $\mathbf{0 . 7 2 3}$ & 0.254 & 0.259 & 0.233 \\
Participatory Planning & 0.122 & $\mathbf{0 . 6 5 5}$ & -0.166 & 0.497 & -0.512 \\
\hline Quality Improvement & 0.378 & $\mathbf{- 0 . 9 1 2}$ & 0.542 & -0.521 & 0.245 \\
Cost reduction & -0.456 & $\mathbf{0 . 7 1 1}$ & 0.197 & 0.169 & 0.314 \\
\hline Integrating process & 0.289 & 0.456 & -0.368 & 0.228 & 0.522 \\
\hline Innovation ability & -0.399 & 0.523 & $\mathbf{- 0 . 9 0 2}$ & 0.349 & 0.316 \\
\hline Multi-functional staff & 0.458 & 0.469 & $\mathbf{0 . 6 8 9}$ & -0.167 & -0.233 \\
\hline Continuous staff training and development & 0.478 & 0.328 & $\mathbf{0 . 8 2 6}$ & 0.258 & 0.147 \\
\hline New product introduction & -0.359 & -0.510 & 0.228 & 0.394 & $\mathbf{0 . 8 5 5}$ \\
\hline Innovation based on customer requirements & 0.237 & 0.213 & 0.391 & -0.229 & $\mathbf{- 0 . 6 1 2}$ \\
\hline Customer satisfaction & 0.347 & 0.414 & 0.146 & 0.501 & $\mathbf{0 . 7 2 6}$ \\
\hline Delivery Speed & 0.449 & 0.359 & 0.511 & 0.210 & $\mathbf{- 0 . 8 1 9}$ \\
\hline Retain and grow customer relationships & 0.492 & -0.158 & 0.527 & -0.109 & $\mathbf{0 . 6 8 8}$ \\
\hline Close relationships with supplier & $\mathbf{0 . 8 1 9}$ & 0.264 & -0.378 & 0.492 & -0.167 \\
\hline Strategic relationship with customers & $\mathbf{0 . 7 3 2}$ & 0.339 & 0.412 & 0.307 & 0.237 \\
\hline Customer and supplier confidence & $\mathbf{0 . 7 1 4}$ & 0.421 & 0.119 & 0.408 & -0.126 \\
\hline Using modern communication equipment & -0.286 & 0.552 & 0.479 & $\mathbf{0 . 6 9 5}$ & 0.511 \\
\hline E-commerce capabilities & 0.349 & -0.229 & -0.468 & $\mathbf{- 0 . 8 7 9}$ & 0.389 \\
\hline Ability of IT in companies & 0.211 & 0.196 & 0.339 & $\mathbf{0 . 7 5 5}$ & 0.228 \\
\hline Technological cooperation & 0.159 & 0.488 & -0.257 & 0.230 & 0.119 \\
\hline
\end{tabular}

\subsection{Preference of ASC activities}

Table 4 presents the means and standard deviations of all initial components, comparing importance and priority among the five final components of ASC. The means of the factor 1 (F4) obviously indicate the highest value followed by the means of the F5. F2 and F1 account for the third and fourth highest measures and F3 indicates the lowest means. These high mean values explain that respondent firms have recognized the importance of each ASC activity.

Table 4

Mean values of activities

\begin{tabular}{clccccc}
\hline \multicolumn{1}{c}{ Initial activities } & $\mathrm{N}$ & Minimum & Maximum & Mean & Std. deviation \\
\hline \multirow{5}{*}{ Factors } & & 180 & 2 & 5 & 4.19 & 0.921 \\
& Integrating business & 180 & 1 & 5 & 3.68 & 1.023 \\
& Product and process development cycle & 180 & 1 & 5 & 3.89 & 0.978 \\
& Participatory Planning & 180 & 1 & 5 & 3.77 & 0.966 \\
& Quality Improvement & 180 & 1 & 5 & 3.85 & 1.003 \\
& Cost reduction & 180 & 1 & 5 & 3.06 & 0.971 \\
F3 & Innovation ability & 180 & 1 & 4 & 2.96 & 0.996 \\
& Multi-functional staff & 180 & 1 & 4 & 2.99 & 0.906 \\
& Continuous staff training and development & 180 & 2 & 5 & 4.09 & 0.982 \\
& New product introduction & 180 & 1 & 5 & 3.68 & 0.965 \\
F5 & Innovation based on customer requirements & 180 & 1 & 5 & 3.89 & 1.056 \\
& Customer satisfaction & 180 & 2 & 5 & 4.02 & 0.964 \\
& Delivery Speed & 180 & 1 & 5 & 3.95 & 0.981 \\
& Retain and grow customer relationships & 180 & 1 & 5 & 3.77 & 1.022 \\
F1 & Close relationships with supplier & 180 & 1 & 5 & 3.67 & 1.009 \\
& Strategic relationship with customers & 180 & 1 & 5 & 3.86 & 0.992 \\
& Customer and supplier confidence & 180 & 2 & 5 & 4.24 & 0.986 \\
& F5 & 180 & 2 & 5 & 4.02 & 1.011 \\
& E-commerce capabilities & 180 & 1 & 5 & 3.98 & 0.979 \\
\hline
\end{tabular}

We have described these five final components referring to related literature and made a preference list as Table 5. 
Table 5

Preference list of the factors

\begin{tabular}{ccc}
\hline Preference & Factors & Description of ASC factors \\
\hline 1 & F4 & Technological activities of ASC \\
2 & F5 & Market and customers demands \\
3 & F2 & Structure and Process of ASC \\
4 & F1 & ASC culture \\
5 & F3 & Management and staff \\
\hline
\end{tabular}

\subsection{ASC portfolio}

According to the preference list, SAPKO firm develops its ASC portfolio on the competence emergency matrix shown in Fig. 3. Our finding illustrates that Technological activities of ASC (F4) and Market and customers (F5) lie in the area of high relevance and high emergency of the matrix. Structure and process of ASC (F2) and ASC culture (F1) might be situated either in the area of high relevance and low emergency or of low relevance and high emergency depending on the interest and size of the company. Management and staff (F3) is located in the area of low relevance and low emergency of the matrix.

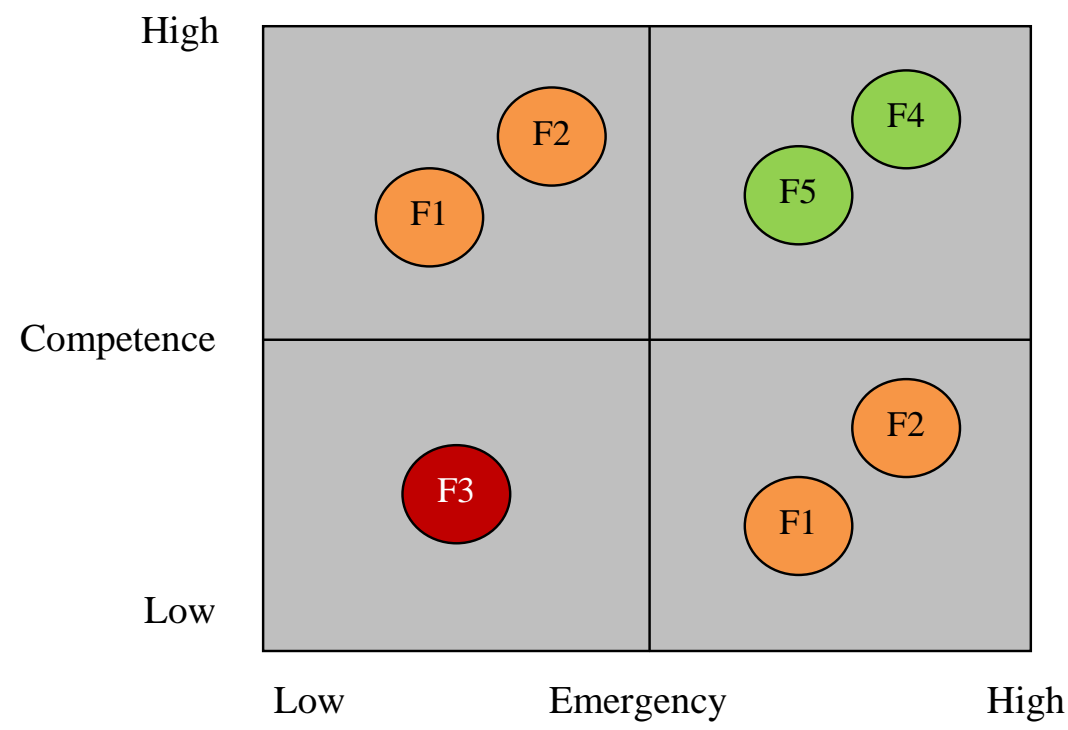

\section{Conclusion}

Fig. 3. Service R\&D portfolio

In this paper, we have used factor analysis and principal component analysis method to provide an analytical model for classification agile supply chain activities for SAPCO Company. Initially, we identified activities associated with agile supply chain used from factor analysis for explanation and classification of activities, which are still unclear for SAPCO Company. The results of this paper have provided five categories in the field of the agile supply chain for SAPCO Company and we have classified them. In this paper, based on competence-emergency matrix we suggested agile supply chain activities portfolio and emphasize patterns and priorities of the agile supply chain for SAPCO Company. Based on the results of matrix portfolio technological activities and market and customers demands were identified as the most important activities and structure and process of agile supply chain , culture and management and staff were placed in the next category. 
For future research, we propose to identify more activities associated with agile supply chain and use them for better decision making in the field of selecting the suppliers and more efficient agile supply chain. Furthermore, the methodology of this study can be used in other fields of industries.

\section{Acknowledgment}

This authors would like to thank the anonymous referee for their comments on earlier versions of this paper.

\section{References}

Arteta, B.M., \& Giachetti, R.E. (2004). A measure of agility as the complexity of the enterprise system. Journal of Robotics and Computer Integrated Manufacturing, 20, 495-503.

Cagliano, R., Caniato, F., \& Spina, G. (2004). Lean, agile and traditional supply: how do they impact manufacturing performance. Journal of Purchasing and Supply Management, 10, 151-164.

Chen, C.T., Lin, C.T., \& Huang, S.F. (2006). A fuzzy approach for supplier evaluation and selection in supply chain management, International Journal of Production Economics, 102, 289-301.

Christopher, M. (2000). The agile supply chain - competing in volatile markets. Industrial Marketing Management, 29, 37-44.

Dickson, G. (1966). An analysis of vendor selection systems and decisions. Journal of Purchasing, 2 (1), 5-17.

Elkins, D.A., Huanga, N.J, \& Alden, J.M. (2004). Agile manufacturing systems in the automotive industry. International Journal of Production Economics, 91, 201-214.

Field, A.P. (2005). Factor analysis on SPSS. In: Discovering statistics using SPSS. $2^{\text {nd }}$ ed. London, UK: Sage.

Ghosh, S., \& Jintanapakanont, J. (2004). Identifying and assessing the critical risk factors in an underground rail project in Thailand: a factor analysis approach, International Journal of Project Management, 22, 633-643.

Goldman, S.L., Nagel, R.N., \& Preiss, K. (1995). Agile Competitors and Virtual OrganizationsStrategies for Enriching the Customer. Van Nostrand Reinhold, New York.

Gunasekaran, A. (1998). Agile manufacturing: Enablers and an implementation framework. International Journal of Production Research, 36 (5), 1223-1247.

Gunasekaran, A. (1999). Editorial: Design and implementation of agile manufacturing systems. International Journal of Production Economics, 62, 1-6.

Heide, J.B., \& John, G. (1990). Alliances in industrial purchasing: the determinants of joint action in buyer-supplier relationships. Journal of Marketing Research, 27 (1), 24-36.

Hellard, R.B. (1995). Project Partnering Principle and Practice. Thomas Telford Publications, London.

Hu, L., \& Bentler, P. M. (1999). Cutoff criteria for fit indexes in covariance structure analysis: Conventional criteria versus new alternatives. Structural Equation Modeling, 6, 1-55.

Jolliffe, I. T. (2002). Principal component analysis, Springer series in statistics (2nd). New York: Springer.

Lee, Y., \& Lee, H. (2011). Application of factor analysis for service R\&D classification: A case study on the Korean ICT industry. Expert Systems with Applications, 38, 2119-2124.

Luo, X., Wu, C., Rosenberg, D. \& Barnes, D. (2009). Supplier selection in agile supply chains: An information-processing model and an illustration. Journal of Purchasing \& Supply Management, 15, 249-262.

Masson, R., Iosif, L., MacKerron, G., \& Fernie, J. (2007). Managing complexity in agile global fashion industry supply chains. International Journal of Logistics Management, 18 (2), 238-254.

Ocal, E.M, Oral, E.L, Erdis, E., \& Vural, G. (2007). Industry financial ratios-application of factor analysis in Turkish construction industry. Building and Environment, 42, 385-392. 
Parasuraman, A., Grewal, D., \& Krishnan, R. (2004). Marketing research. Boston, New York: Houghton Mifflin Company.

Power, D. J., Sohal, A.S., \& Rahman, S.U., (2001). Critical success factors in agile supply chain management: an empirical study. International Journal of Physical Distribution and Logistics Management, 31 (4), 247-265.

Prater, M., Biehl, M., \& Smith, M. (2001). International supply chain agility-tradeoffs between flexibility and uncertainty. International Journal of Operations \& Production Management, 21(56), 823-839.

Sarkis, J. (2001). Benchmarking for agility. Benchmarking: An International Journal, 8 (2), 88-107.

Smith, L. I. (2002). A tutorial on principal components analysis. <http://www.cs. otago.ac.nz/cosc453/student_tutorials/principal_components.pdf $>$.

Song, M., Fu R.X., Zhu C., Xin Z. H. (2007). Study on the agile supply chain management based on agent. The Journal of China Universities of Posts and Telecommunications, 14, 115-118.

Stevens, J. (1986). Factor analysis. In: Applied multi varied statistics for the social sciences. Hillsdale, NJ: Lawrence Erlbaum Associates.

Storey, J., Emberson, C., \& Reade, D., (2005). The barriers to customer responsive supply chain management. International Journal of Operations \& Production Management, 25 (3), 242-260.

Strattona, R., \& Warburton, R.D.H. (2003). The strategic integration of agile and lean supply. International Journal of Production Economics, 85,183-198.

Tziakas, D.N, Chalikias, G.K., Kaski, J.C, Kekes, A., Hatzinikolaou, E.I, Stakos, D.A, Tentes , I.K., Kortsaris, A.X, \& Hatseras, D.I. (2007). Inflammatory and anti-inflammatory variable clusters and risk prediction in acute coronary syndrome patients: A factor analysis approach, Atherosclerosis, 193, 196-203.

Weber, C.A., Ellram, L.M., (1993). Supplier selection using multi-objective programming: a decision support system approach. International Journal of Physical Distribution and Logistics Management, 23 (2), 3-14.

Xia, W., \& Wu, Z. (2007). Supplier selection with multiple criteria in volume discount environments. Omega, 35, 494-504.

Yusuf, Y.Y., Sarhadi, M., \& Gunasekaran, A. (1999). Agile manufacturing: the drivers, concepts and attributes. International Journal of Production Economics, 62, 33-43. 